\title{
An Optical Model for the Remote-Sensing of Absorption Coefficients of Phytoplankton in Oceanic/Coastal Waters
}

\author{
Surya Prakash Tiwari, Palanisamy Shanmugam \\ Department of Ocean Engineering, Indian Institute of Technology Madras, Chennai, India \\ Email: pshanmugam@iitm.ac.in
}

Received July 2, 2012; revised July 31, 2012; accepted August 20, 2012

\begin{abstract}
A new model for the remote sensing of absorption coefficients of phytoplankton $a_{p h}(\lambda)$ in oceanic and coastal waters is developed and tested with SeaWiFS and MODIS-Aqua data. The model is derived from a relationship of the remote sensing reflectance ratio $R_{r s}(670) / R_{r s}(490)$ and $a_{p h}(\lambda)$ (from large in-situ data sets). When compared with over 470 independent in-situ data sets, the model provides accurate retrievals of the $a_{p h}(\lambda)$ across the visible spectrum, with mean relative error less than $8 \%$, slope close to unity and $\mathrm{R}^{2}$ greater than 0.8 . Further comparison of the SeaWiFS-derived $a_{p h}(\lambda)$ with in-situ $a_{p h}(\lambda)$ values gives similar and consistent results. The model when used for analysis of MODIS-Aqua imagery, provides more realistic values of the phytoplankton absorption coefficients capturing spatial structures of the massive algal blooms in surface waters of the Arabian Sea. These results demonstrate that the new algorithm works well for both the coastal and open ocean waters observed and suggest a potential of using remote sensing to provide knowledge on the shape of phytoplankton absorption spectra that are a requirement in many inverse models to estimate phytoplankton pigment concentrations and for input into bio-optical models that predict carbon fixation rates for the global ocean.
\end{abstract}

Keywords: Remote Sensing; Phytoplankton Absorption; Bio-Optical Models; Coastal Waters; MODIS-Aqua; SeaWiFS; Arabian Sea

\section{Introduction}

Phytoplanktons play a critical role in the cycling of biogeochemical properties, and are responsible for much of the oxygen present in the Earth's atmosphere through a process known as photosynthesis. Their cumulative energy fixation in carbon compounds that account for approximately half of the world's total primary productivity is the basis for the majority of oceanic food chains. They are highly diverse in shape, size, and pigmentation, having a predominant influence on the colour of seawater measured by satellite sensors $[1,2]$.

Light absorption by particulate phytoplankton - which determines the amount of radiant energy captured by them - is an important source of optical variability in surface waters of the ocean. This variability has consequences for light attenuation, primary production, remote sensing of pigment biomass and mixed layer heating [3-8]. The spectra of phytoplankton absorption $\left(a_{p h}(\lambda)\right)$ vary widely both in terms of magnitude and spectral behaviour [9-11] in seawaters because of differences in phytoplankton community, cell size, and pigment packages among sites [11-13]. For these reasons and because of the advent of remote sensing capabilities, there is increasing demand for a fundamental knowledge of the magnitude, range and sources of variability in phytoplankton optical properties in marine surface waters. Remote sensing offers the potential for synoptic assessment of pigment biomass and primary production, but this requires the ability to accurately estimate phytoplankton absorption coefficients from remotely measured signals using an appropriate optical model that has potential applications in ocean colour remote sensing.

To estimate $a_{p h}(\lambda)$ coefficients from remote sensing data, several models have been reported in the recent studies which enable retrieval of two or more in-water constituents and properties simultaneously. For these models, an inversion technique is usually applied to a parameterized ocean colour model whose parameters have been determined from in-situ bio-optical measurements. Garver and Siegel [14] developed a nonlinear statistical method for the inversion of ocean colour data, which assumed the known spectral shapes of specific absorption coefficients for phytoplankton. Later, this model was improved and optimized by Maritorena et al. [15] (the GSM01 model) using simulated annealing, thus the model could be applied to global ocean colour data for improved retrievals of pigment concentrations. However, GSM model provides absorption coefficients of phytoplankton at spe- 
cific wavelengths. Lee et al. [16] developed a multiband quasi-analytical model (QAA) based on the relationships between remote sensing reflectance and IOPs of water derived from the radiative transfer equation. Though the QAA model provides $a_{p h}(\lambda)$ within $\sim 15 \%$ of the input values [16] in open ocean waters, it yields $a_{p h}$ values at specific wavelengths in the blue-green domain and significantly large errors (> 27\%) in coastal waters [17]. Smyth et al. (2006) developed a semi-analytical model to the problem of determining inherent optical properties (IOPs) from satellite and in-situ ocean colour data. This model has the same limitations as other models producing large errors particularly at $555 \mathrm{~nm}$ (see Figure 5 in Smyth et al. [18]). Boss and Roesler [19] developed a constrained linear matrix inversion model with statistical selection to obtain absorption coefficients of phytoplankton and other IOPs from the ocean radiance. An evaluation of these models in a recent study from coastal waters indicated that the spectrum of $a_{p h}(\lambda)$ is currently obtainable for only few wavelengths within the blue-green domain; this causes the main difficulty in making the models more usable with any suite of wavelengths. Thus, it is unrealistic to consider an optimized hyperspectral version of the model with the current parameterization for $a_{p h}(\lambda)$.

Since information on chlorophyll and its accessory pigments can help the differentiation into major phytoplankton classes or taxonomic groups [9], it would be a great enhancement to ocean-colour remote sensing if information regarding these pigments can be retrieved accurately from water colour. In this study, a new optical model is developed to provide accurate assessments of the $a_{p h}(\lambda)$ spectra from ocean-colour remote sensing data. The model validation is performed with three independent data sets such as NOMAD-2, Carder datasets, and NOMAD SeaWiFS match-ups. The model results show very good agreement with in situ and satellite data sets, since it relies primarily on $a_{p h}$ peaks at 443 and $670 \mathrm{~nm}$ wavelengths that are much influenced by phytoplankton absorption. Further, the applicability of the new model to process MODIS/Aqua and identify the distribution pattern of phytoplankton absorption coefficient in the Arabian Sea is examined.

\section{Methods}

\subsection{Absorption by Phytoplankton}

The beam attenuation coefficient $\mathrm{c}\left(\mathrm{m}^{-1}\right)$ is the sum of the total seawater absorption combined with the rate of the photon losses due to scattering in water column:

$$
c(\lambda)=a_{t}(\lambda)+b(\lambda)
$$

where, $c(\lambda)$ is the total attenuation coefficient, $a_{t}(\lambda)$ is the total absorption coefficient, and $b(\lambda)$ is the total scattering coefficient (units in $\mathrm{m}^{-1}$ for all three parameters). In this equation, $a_{t}(\lambda), b(\lambda)$, and $c(\lambda)$ are all IOP's of the water column. Scattering can be further characterized in terms of the angular distribution of the scattered light [20], which is beyond the scope of the present study. An analysis of the light absorption component provides valuable insights into the relative importance of CDOM and phytoplankton to light availability and ocean colour, as it is a measure of an inherent optical property (IOP) of the water [21], which means that, it is a property of oceanic waters fully dependent on the water composition. The total absorption coefficient can be expressed as a sum of the individual contribution of four major absorption coefficients of ocean water: pure seawater, $a_{w}(\lambda)$, phytoplankton, $a_{p h}(\lambda)$, coloured dissolved organic matter, $a_{g}(\lambda)$, and suspended sediments, $a_{d}(\lambda)$ :

$$
a_{t}(\lambda)=a_{w}(\lambda)+a_{p h}(\lambda)+a_{g}(\lambda)+a_{d}(\lambda)
$$

where $a_{w}(\lambda)$ is assumed to be a known constant [22,23]. In oceanic waters, IOPs of all the optically active substances (except pure seawater) are assumed to covary with chlorophyll-a (Chl-a) concentration [1]. The standard parameterizations of the IOP models have been proposed and widely used for the remote sensing applications in the visible region, still the spectral characterization of IOPs is much less documented and currently the open field of the investigation. Here, phytoplankton absorption coefficient is the primary interest which is usually described by a power, hyperbolic and $2^{\text {nd }}$ order polynomial function [24].

Phytoplankton absorption coefficient is directly proportional to chlorophyll pigment concentrations;

$$
a_{p h}(\lambda) \propto<C h l>.
$$

Generally we can write it as,

$$
a_{p h}(\lambda)=a_{p h} *(\lambda)<C h l>
$$

where $a_{p h} *(\lambda)$ is the chlorophyll-specific absorption coefficient (that varies widely depending on light history, nutrient availability, and species).

A more robust relationship can be expressed based on Bricaud et al. [24-26]:

$$
a_{p h}(\lambda)=A(\lambda)<C h l>^{B(\lambda)}
$$

where $A(\lambda)$ and $B(\lambda)$ are the spectral coefficients, and vary widely depending on light history, nutrient availability, and species composition. It is, of course, induced by the other optically active substances in the ocean.

\subsection{Modelling Approach}

A new inversion model for determining $a_{p h}(\lambda)$ is developed based on the remote sensing reflectance ratio $\left(R_{r s}(670) / R_{r s}(490)\right)$ and $a_{p h}(\lambda)$ values in the visible and near-infrared wavelengths (400 nm - $700 \mathrm{~nm}$ ) (Figure 1). This model gives estimates of the $a_{p h}$ with specified $R_{r s}(\lambda)$ 
values like the chlorophyll (Chl) parameterization. Similar parameterizations for determining the shapes of $a_{p h}(\lambda)$ for all wavelengths (400 nm - $700 \mathrm{~nm}$ ) are derived (Figure 2, Table 1). The relationships between the spectral absorption coefficients of phytoplankton at 443 and $670 \mathrm{~nm}$ versus the remote sensing reflectance ratio $\left(R_{r s}(670) / R_{r s}(490)\right)$ provide the best-fit relationships with notably high correlation coefficients for these wavelengths. The model constants obtained from these relationships represent a third order polynomial equation which takes the form of equation:

$$
a_{p h}(\lambda)=a_{0}(\lambda)+a_{1}(\lambda) \times X+a_{2}(\lambda) \times X^{2}+a_{3}(\lambda) \times X^{3}
$$

where the $X$ refers to the spectral band ratio of the remote sensing reflectance i.e., $X=\log _{10}\left[R_{r s}(670) / R_{r s}(490)\right]$, and the phytoplankton absorption coefficient term can be expressed by non-linear cubic polynomial model given as below:

$$
\begin{aligned}
a_{p h}(\lambda)= & a_{0}(\lambda)+a_{1}(\lambda) \times \log _{10}\left[\frac{R_{r s}(670)}{R_{r s}(490)}\right]+a_{2}(\lambda) \\
& \times \log _{10}\left[\frac{R_{r s}(670)}{R_{r s}(490)}\right]^{2}+a_{3}(\lambda) \times \log _{10}\left[\frac{R_{r s}(670)}{R_{r s}(490)}\right]^{3}
\end{aligned}
$$

By using a linear extrapolation method the wavelength dependent constant coefficients are determined for all the wavelengths (400 nm - $700 \mathrm{~nm}$ ) (Figure 2). In the above equations, $\lambda$ is the wavelength, and $a_{0}, a_{1}, a_{2}$, and $a_{3}$ are the constants. The spectral values of the coefficients $a_{0}$, $a_{1}, a_{2}$, and $a_{3}$ of the cubic equation represent the variation of $a_{p h}(\lambda)$ as a function of remote sensing reflectance ratio at 670 and $490 \mathrm{~nm}$. Thus, this model can be easily applied to any other independent data set and generalized for other types of phytoplankton absorption coefficient measurements. If some measurements are available, which have explicit non-linear dependence on $a_{p h}(\lambda)$ (Equation (7)), and can be easily computed by the new model. The more precise $a_{p h}$ model can be constructed with the use of some supplementary data in addition to more $R_{r s}(\lambda)$, which has no explicit linear dependence on $a_{p h}(\lambda)$.

Figure 3 shows the tight relationships between the in-situ $a_{p h}(443)$ and $a_{p h}(670)$ and in-situ chlorophyll-a concentrations (top panels). Similar relationships are observed between the model-derived $a_{p h}(443)$ and $a_{p h}(670)$ and in-situ chlorophyll-a concentrations (bottom panels), The range of $a_{p h}(\lambda)$ value varied from $0.001\left(\mathrm{~m}^{-1}\right)-1$ $\left(\mathrm{m}^{-1}\right)$ corresponding to a wide rage of the different $\mathrm{Chl}$ concentrations $0.01\left(\mathrm{mg} \cdot \mathrm{m}^{-3}\right)-100\left(\mathrm{mg} \cdot \mathrm{m}^{-3}\right)$.

\subsection{Assessment of Model Performance}

The performance of the new model is assessed by com- paring its predicted $a_{p h}(\lambda)$ values with in situ $a_{p h}(\lambda)$ values. Three basic statistical methods are used such as the mean normalized bias (MNB), root mean square error (RMSE), and mean relative error (MRE). The accuracy of $a_{p h}(\lambda)$ predictions (for all data acquired) is also assessed based on the slope (S), intercept (I), and correlation coefficient $\left(\mathrm{R}^{2}\right)$ of the linear regression between the in-situ and predicted $a_{p h}(\lambda)$ values Systematic and random errors are characterized by the mean relative error (MRE) and root mean square error (RMSE), respectively (IOCCG, 2006); these metrics are defined as:

$$
\begin{aligned}
& \mathrm{RMSE}=\left(\frac{\sum_{\mathrm{i}=1}^{\mathrm{N}}\left[\log \left(a_{\text {phi }}^{\text {predicted }}\right)-\log \left(a_{\text {phi }}^{\text {insitu }}\right)\right]^{2}}{\mathrm{~N}-2}\right)^{1 / 2} \\
& \mathrm{MRE}=\sum_{i=1}^{N} \frac{\log \left(a_{p h i}^{\text {predicted }}\right)-\log \left(a_{\text {phi }}^{\text {insitu }}\right)}{\log \left(a_{\text {phi }}^{\text {insitu }}\right)} \times 100 \% \\
& \mathrm{MNB}=\frac{1}{N} \sum_{i=1}^{N} \frac{\log \left(a_{\text {phi }}^{\text {predicted }}\right)-\log \left(a_{\text {phi }}^{\text {insitu }}\right)}{\log \left(a_{\text {phi }}^{\text {insitu }}\right)}
\end{aligned}
$$

where $a_{\text {phi }}^{\text {predicted }}$ stands for the model-derived values, $a_{p h i}^{\text {insitu }}$ stands for the in-situ measurements, and $\mathrm{N}$ is the number of valid retrievals. The root mean square error (RMSE) for the derived $a_{p h}(\lambda)$ is calculated based on the comparison of in-situ data with model data for the key SeaWiFS wavelengths 412, 443, 490, 510, 530, 555, 670, and $683 \mathrm{~nm}$. These errors are calculated after the log transformation. Table 2 summarizes the statistical results of the new model validation with an in situ datasets.

\section{Data Sets}

\subsection{In-Situ Data}

An updated NASA bio-Optical Marine Algorithm Dataset (hereafter referred to as NOMAD) was obtained from the NASA Ocean Biology Processing Group. The NOMAD dataset is a global, high quality in-situ bio-optical data set collected over a wide range of optical properties, trophic status, and geographical locations in open ocean waters, estuaries, and coastal waters (including Arabian Sea and coastal waters of India). It consists of two types of datasets; i.e., the in-situ bio-optical data set and concurrent SeaWiFS observations of the remote sensing reflectance $R_{r s}(\lambda)$ at key wavelengths. These datasets are acquired over 4459 stations and stored in the system for use in algorithm development and validation (O'Reilly et al., 1998, 2000). The NOMAD in-situ data sets split into two data sets in the present study, namely NOMAD-1 and NOMAD-2. It should be noted that the NOMAD-1 in-situ data set is used for model parameterizations, whilst another suite of NOMAD-2 data set (composed of 

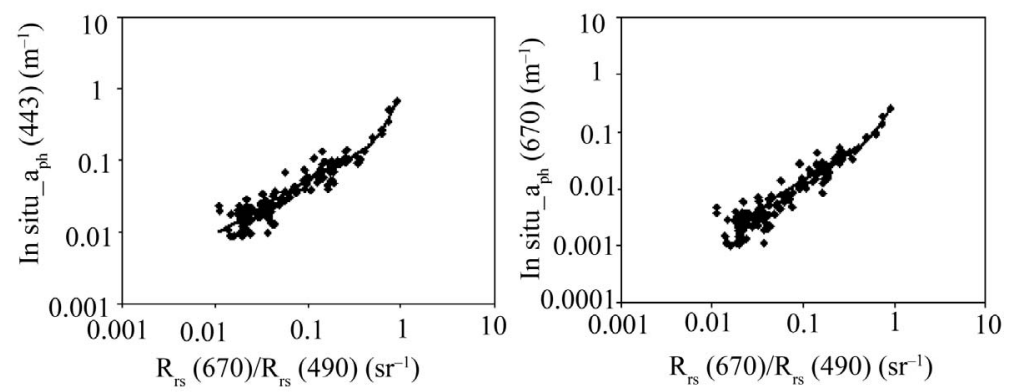

Figure 1. Relationships between the $a_{p h}(443)$ and $a_{p h}(670)$ and remote sensing reflectance ratio $R_{r s}(670) / R_{r s}(490)$ from the NOMAD in-situ dataset $(\mathrm{N}=102)$.
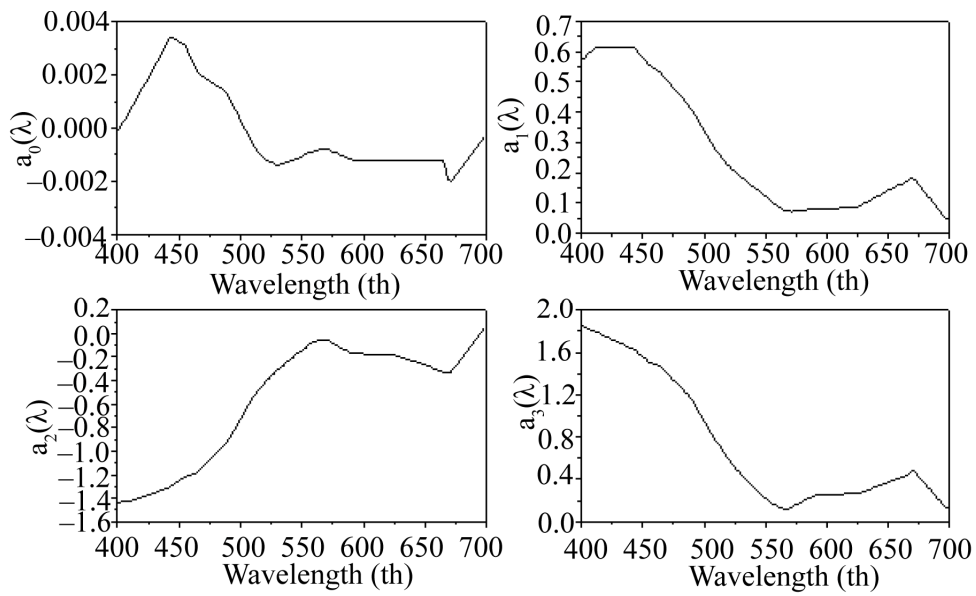

Figure 2. Spectral values of the coefficients $a_{0}, a_{1}, a_{2}$, and $a_{3}$ of the cubic equations representing the variation of $a_{p h}(\lambda)$ as a function of the remote sensing reflectance ratio at $670 \mathrm{~nm}$ and $490 \mathrm{~nm}$. The coefficients values in Table 1 were obtained by interpolation and extrapolation techniques.

in-situ data of $a_{p h}(\lambda)$ and coincidently measured SeaWiFS-remote sensing reflectances) are used for the model validation. The Carder bio-optical dataset $(\mathrm{N}=$ 477) obtained during cruises in the west coast of Florida in different seasons and years from 1999 to 2006 are also used to validate the performance of the proposed model. Only stations having both optical and pigments measurements are considered in this study.

\subsection{Satellite Data and Processing}

MODIS-Aqua Level 1A data $(\sim 1 \mathrm{~km}$ pixel-1 at nadir, local area coverage (LAC) of the Arabian Sea collected on 18 Feb. 2010, was obtained from the NASA Goddard Space Flight Centre (http://oceancolour.gsfc.nasa.gov/). The MODIS L1A data that consisted of calibrated and scaled top of atmospheric radiances $\left(L_{t}(\lambda)\right)$ was input to the SeaDAS atmospheric correction code to output the Rayleigh-corrected $\left(L_{r c}(\lambda)\right)$ radiances at all wavelengths. Both $L_{t}(\lambda)$ and $L_{r c}(\lambda)$ were input to the CAAS algorithm [27] to retrieve the desired water-leaving radiance products. Before applying these corrections, an operational cloud-masking scheme for all MODIS-Aqua data was adopted to create flags over the cloud-covered regions.
The resulting products were converted to the remote sensing reflectance $\left(R_{r s}\right)$ and processed to the Level 2 products such as $a_{p h}(\lambda)$. For comparison purpose, the SeaDAS software was used to produce $L_{w}(\lambda)$ products for the same area.

\section{Results}

\subsection{Algorithm Validation}

To assess the performance of the new model, it was applied to three independent data sets: NOMAD-2, Carder datasets, and NOMAD SeaWiFS match-ups, and the resulting statistical errors were analysed. The applicability of this model to satellite ocean colour remote sensing data is discussed in detail.

\subsubsection{Comparison with NOMAD-2 In-Situ Data Set}

Figure 4 shows the comparison between the model-derived $a_{p h}(\lambda)$ values and in-situ $a_{p h}(\lambda)$ from the NOMAD-2 data set. Table 2 presents the error statistics at the selected wavelengths from 412 to $683 \mathrm{~nm}$. It can be seen from these scatter plots that the model-derived $a_{p h}(\lambda)$ agree very well with $i n$-situ $a_{p h}(\lambda)$ (i.e., 1:1 correlation) at all 
Table 1. Spectral values of the constants obtained when fitting the variations of absorption by phytoplankton $a_{p h}(\lambda)$ versus the remote sensing reflectance ratio $\left[R_{r s}(670) / R_{r s}(490)\right]$ to cubic equation of the form $a_{p h}(\lambda)=a_{0}(\lambda)+a_{1}(\lambda) \times X+a_{2}(\lambda) \times X^{2}$ $+a_{3}(\lambda) \times X^{3}$. Wavelength dependent coefficients were derived using the linear extrapolation and interpolation technique.

\begin{tabular}{|c|c|c|c|c|c|c|c|c|c|}
\hline$\lambda(\mathrm{nm})$ & $a_{0}$ & $a_{1}$ & $a_{2}$ & $a_{3}$ & $\lambda(\mathrm{nm})$ & $a_{0}$ & $a_{1}$ & $a_{2}$ & $a_{3}$ \\
\hline 400 & -0.0002 & 0.57118 & -1.43557 & 1.84816 & 551 & -0.0011 & 0.11798 & -0.13456 & 0.20622 \\
\hline 402 & 0.00001 & 0.57915 & -1.43387 & 1.83824 & 553 & -0.001 & 0.11074 & -0.11848 & 0.18786 \\
\hline 405 & 0.00024 & 0.59111 & -1.43131 & 1.82336 & 555 & -0.0009 & 0.1035 & -0.1024 & 0.1695 \\
\hline 407 & 0.00039 & 0.59908 & -1.42961 & 1.81344 & 557 & -0.0009 & 0.09706 & -0.08956 & 0.15546 \\
\hline 409 & 0.00055 & 0.60706 & -1.4279 & 1.80352 & 559 & -0.0009 & 0.09062 & -0.07672 & 0.14142 \\
\hline 411 & 0.0007 & 0.61503 & -1.4262 & 1.7936 & 561 & -0.0009 & 0.08528 & -0.06762 & 0.13168 \\
\hline 413 & 0.00087 & 0.61496 & -1.41881 & 1.78293 & 563 & -0.0008 & 0.08104 & -0.06226 & 0.12624 \\
\hline 415 & 0.00104 & 0.61489 & -1.41141 & 1.77225 & 565 & -0.0008 & 0.0768 & -0.0569 & 0.1208 \\
\hline 417 & 0.00121 & 0.61481 & -1.40402 & 1.76158 & 567 & -0.0008 & 0.07436 & -0.0569 & 0.12252 \\
\hline 421 & 0.00155 & 0.61467 & -1.38923 & 1.74023 & 571 & -0.0008 & 0.07113 & -0.06272 & 0.13133 \\
\hline 423 & 0.00172 & 0.6146 & -1.38183 & 1.72955 & 573 & -0.0009 & 0.07199 & -0.07436 & 0.1438 \\
\hline 425 & 0.00189 & 0.61453 & -1.37444 & 1.71888 & 575 & -0.0009 & 0.07285 & -0.086 & 0.15628 \\
\hline 427 & 0.00207 & 0.61445 & -1.36705 & 1.7082 & 577 & -0.0009 & 0.07371 & -0.09764 & 0.16874 \\
\hline 429 & 0.00224 & 0.61438 & -1.35965 & 1.69753 & 579 & -0.001 & 0.07457 & -0.10928 & 0.18121 \\
\hline 431 & 0.00241 & 0.61431 & -1.35226 & 1.68685 & 581 & -0.001 & 0.07543 & -0.12092 & 0.19369 \\
\hline 433 & 0.00258 & 0.61424 & -1.34486 & 1.67618 & 583 & -0.0011 & 0.07629 & -0.13256 & 0.20615 \\
\hline 435 & 0.00275 & 0.61417 & -1.33747 & 1.6655 & 585 & -0.0011 & 0.07715 & -0.1442 & 0.21862 \\
\hline 437 & 0.00292 & 0.6141 & -1.33007 & 1.65483 & 587 & -0.0011 & 0.07801 & -0.15584 & 0.23109 \\
\hline 441 & 0.00326 & 0.61395 & -1.31528 & 1.63348 & 591 & -0.0012 & 0.07946 & -0.17335 & 0.2503 \\
\hline 443 & 0.00343 & 0.61388 & -1.30789 & 1.6228 & 593 & -0.0012 & 0.07979 & -0.17344 & 0.2513 \\
\hline 445 & 0.00338 & 0.60432 & -1.29259 & 1.60358 & 595 & -0.0012 & 0.08011 & -0.17354 & 0.2523 \\
\hline 447 & 0.00332 & 0.59475 & -1.27729 & 1.58437 & 597 & -0.0012 & 0.08043 & -0.17364 & 0.2533 \\
\hline 449 & 0.00326 & 0.58519 & -1.262 & 1.56515 & 599 & -0.0012 & 0.08076 & -0.17373 & 0.2543 \\
\hline 451 & 0.00321 & 0.57563 & -1.2467 & 1.54593 & 601 & -0.0012 & 0.08108 & -0.17383 & 0.2553 \\
\hline 453 & 0.00315 & 0.56606 & -1.2314 & 1.52672 & 603 & -0.0012 & 0.08141 & -0.17393 & 0.2563 \\
\hline 455 & 0.0031 & 0.5565 & -1.2161 & 1.5075 & 605 & -0.0012 & 0.08173 & -0.17402 & 0.2573 \\
\hline 457 & 0.0029 & 0.55098 & -1.20894 & 1.49868 & 607 & -0.0012 & 0.08206 & -0.17412 & 0.2583 \\
\hline 459 & 0.0027 & 0.54546 & -1.20178 & 1.48986 & 609 & -0.0012 & 0.08238 & -0.17422 & 0.2593 \\
\hline 461 & 0.0025 & 0.53994 & -1.19462 & 1.48104 & 611 & -0.0012 & 0.0827 & -0.17431 & 0.2603 \\
\hline 463 & 0.0023 & 0.53442 & -1.18746 & 1.47222 & 613 & -0.0012 & 0.08303 & -0.17441 & 0.2613 \\
\hline 465 & 0.0021 & 0.5289 & -1.1803 & 1.4634 & 615 & -0.0012 & 0.08335 & -0.17451 & 0.2623 \\
\hline 467 & 0.00203 & 0.51936 & -1.15899 & 1.43891 & 617 & -0.0012 & 0.08368 & -0.1746 & 0.2633 \\
\hline 469 & 0.00197 & 0.50982 & -1.13768 & 1.41442 & 619 & -0.0012 & 0.084 & -0.1747 & 0.2643 \\
\hline 471 & 0.0019 & 0.50028 & -1.11637 & 1.38993 & 621 & -0.0012 & 0.08497 & -0.17743 & 0.2643 \\
\hline
\end{tabular}


Continued

\begin{tabular}{|c|c|c|c|c|c|c|c|c|c|}
\hline 473 & 0.00183 & 0.49073 & -1.09507 & 1.36543 & 623 & -0.0012 & 0.08593 & -0.18017 & 0.2643 \\
\hline 475 & 0.00177 & 0.48119 & -1.07376 & 1.34094 & 625 & -0.0012 & 0.0869 & -0.1829 & 0.2643 \\
\hline 477 & 0.0017 & 0.47165 & -1.05245 & 1.31645 & 627 & -0.0012 & 0.09108 & -0.19 & 0.27277 \\
\hline 479 & 0.00163 & 0.46211 & -1.03114 & 1.29196 & 629 & -0.0012 & 0.09527 & -0.1971 & 0.28124 \\
\hline 481 & 0.00157 & 0.45257 & -1.00983 & 1.26747 & 631 & -0.0012 & 0.09946 & -0.2042 & 0.28971 \\
\hline 483 & 0.0015 & 0.44303 & -0.98852 & 1.24297 & 633 & -0.0012 & 0.10364 & -0.2113 & 0.29818 \\
\hline 485 & 0.00143 & 0.43348 & -0.96722 & 1.21848 & 635 & -0.0012 & 0.10783 & -0.2184 & 0.30665 \\
\hline 487 & 0.00137 & 0.42394 & -0.94591 & 1.19399 & 637 & -0.0012 & 0.11201 & -0.2255 & 0.31512 \\
\hline 489 & 0.0013 & 0.4144 & -0.9246 & 1.1695 & 639 & -0.0012 & 0.1162 & -0.2326 & 0.32359 \\
\hline 491 & 0.00112 & 0.4009 & -0.88879 & 1.13011 & 641 & -0.0012 & 0.12038 & -0.2397 & 0.33206 \\
\hline 493 & 0.00094 & 0.38739 & -0.85298 & 1.09072 & 643 & -0.0012 & 0.12457 & -0.2468 & 0.34053 \\
\hline 495 & 0.00076 & 0.37389 & -0.81717 & 1.05133 & 645 & -0.0012 & 0.12875 & -0.2539 & 0.349 \\
\hline 497 & 0.00058 & 0.36038 & -0.78136 & 1.01194 & 647 & -0.0012 & 0.13294 & -0.261 & 0.35747 \\
\hline 499 & 0.0004 & 0.34688 & -0.74555 & 0.97255 & 649 & -0.0012 & 0.13712 & -0.2681 & 0.36594 \\
\hline 501 & 0.00021 & 0.33337 & -0.70974 & 0.93316 & 651 & -0.0012 & 0.14131 & -0.2752 & 0.37441 \\
\hline 503 & 0.00003 & 0.31987 & -0.67393 & 0.89377 & 653 & -0.0012 & 0.14549 & -0.2823 & 0.38288 \\
\hline 505 & -0.0002 & 0.30636 & -0.63812 & 0.85438 & 655 & -0.0012 & 0.14968 & -0.2894 & 0.39135 \\
\hline 507 & -0.0003 & 0.29286 & -0.60231 & 0.81499 & 657 & -0.0012 & 0.15386 & -0.2965 & 0.39982 \\
\hline 509 & -0.0005 & 0.27935 & -0.5665 & 0.7756 & 659 & -0.0012 & 0.15804 & -0.3036 & 0.40829 \\
\hline 511 & -0.0007 & 0.26745 & -0.53496 & 0.73874 & 661 & -0.0012 & 0.16223 & -0.3107 & 0.41676 \\
\hline 513 & -0.0008 & 0.25715 & -0.50768 & 0.70442 & 663 & -0.0012 & 0.16641 & -0.3178 & 0.42523 \\
\hline 515 & -0.0009 & 0.24685 & -0.4804 & 0.6701 & 665 & -0.0012 & 0.1706 & -0.3249 & 0.4337 \\
\hline 517 & -0.001 & 0.23655 & -0.45312 & 0.63578 & 667 & -0.0016 & 0.17588 & -0.3309 & 0.45566 \\
\hline 519 & -0.0011 & 0.22625 & -0.42584 & 0.60146 & 669 & -0.0019 & 0.18116 & -0.3369 & 0.47762 \\
\hline 521 & -0.0012 & 0.21737 & -0.40219 & 0.57051 & 671 & -0.002 & 0.17883 & -0.32615 & 0.47552 \\
\hline 523 & -0.0013 & 0.20991 & -0.38217 & 0.54293 & 673 & -0.0019 & 0.16889 & -0.29864 & 0.44935 \\
\hline 525 & -0.0013 & 0.20245 & -0.36215 & 0.51535 & 675 & -0.0018 & 0.15895 & -0.27113 & 0.42318 \\
\hline 527 & -0.0013 & 0.19499 & -0.34213 & 0.48777 & 677 & -0.0017 & 0.14902 & -0.24362 & 0.39701 \\
\hline 529 & -0.0014 & 0.18753 & -0.32211 & 0.46019 & 679 & -0.0016 & 0.13908 & -0.21612 & 0.37084 \\
\hline 531 & -0.0014 & 0.18069 & -0.30362 & 0.43485 & 681 & -0.0014 & 0.12914 & -0.18861 & 0.34467 \\
\hline 533 & -0.0014 & 0.17447 & -0.28668 & 0.41175 & 683 & -0.0013 & 0.1192 & -0.1611 & 0.3185 \\
\hline 535 & -0.0013 & 0.16825 & -0.26972 & 0.38865 & 685 & -0.0012 & 0.10926 & -0.13359 & 0.29233 \\
\hline 537 & -0.0013 & 0.16203 & -0.25277 & 0.36555 & 687 & -0.0011 & 0.09932 & -0.10608 & 0.26616 \\
\hline 539 & -0.0013 & 0.15581 & -0.23583 & 0.34245 & 689 & -0.0009 & 0.08938 & -0.07858 & 0.23999 \\
\hline 541 & -0.0012 & 0.14959 & -0.21887 & 0.31935 & 691 & -0.0008 & 0.07945 & -0.05107 & 0.21382 \\
\hline 543 & -0.0012 & 0.14337 & -0.20192 & 0.29625 & 693 & -0.0007 & 0.06951 & -0.02356 & 0.18765 \\
\hline 545 & -0.0012 & 0.13715 & -0.18498 & 0.27315 & 695 & -0.0006 & 0.05957 & 0.00395 & 0.16148 \\
\hline 547 & -0.0012 & 0.13093 & -0.16803 & 0.25005 & 697 & -0.0004 & 0.04963 & 0.03145 & 0.13532 \\
\hline 549 & -0.0011 & 0.12471 & -0.15108 & 0.22695 & 699 & -0.0003 & 0.03969 & 0.05896 & 0.10915 \\
\hline
\end{tabular}

The $\lambda$ is wavelength; $a_{0}, a_{1}, a_{2}$, and $a_{3}$ are constants. 

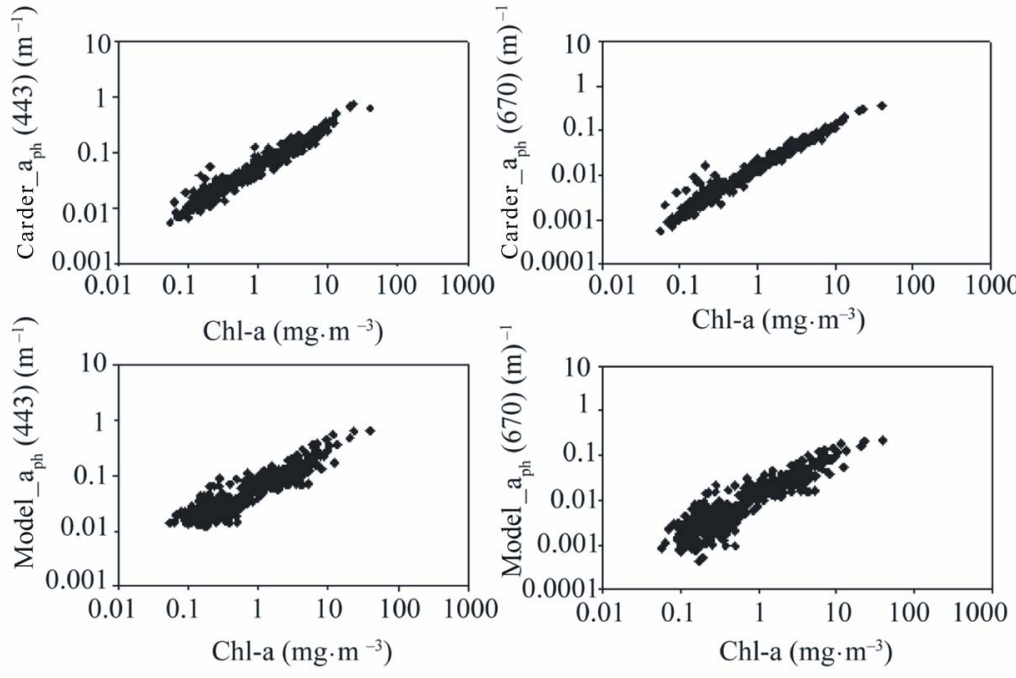

Figure 3. Scatter plots between the Carder in-situ and model $a_{p h}(443)$ and $a_{p h}(670)$ versus chlorophyll concentrations.

Table 2. Statistical comparison between the modeled and in-situ datasets (SeaWiFS, Carder, and NOMAD-2). RMSE, MRE, and $M N B$ and linear-regression results of the datasets at 412, 443, 490, 510, 530, 555, 670, and $683 \mathrm{~nm}$ are also presented.

\begin{tabular}{|c|c|c|c|c|c|c|c|}
\hline IOP's & $R M S E$ & $\operatorname{MRE}(\%)$ & $M N B$ & SLOPE & INTERCEPT & $R^{2}$ & $N$ \\
\hline \multicolumn{8}{|c|}{ NOMAD-2 In situ Data Set } \\
\hline$a_{p h}(412)$ & 0.2387 & 8.06 & 0.0795 & 1.02 & 0.1011 & 0.8572 & 470 \\
\hline$a_{p h}(443)$ & 0.2038 & 4.95 & 0.0475 & 1.009 & 0.0567 & 0.8777 & 470 \\
\hline$a_{p h}(490)$ & 0.2321 & 6.27 & 0.0716 & 1.048 & 0.1305 & 0.8596 & 470 \\
\hline$a_{p h}(510)$ & 0.2408 & 5.17 & 0.0683 & 1.034 & 0.1148 & 0.8682 & 470 \\
\hline$a_{p h}(555)$ & 0.3038 & 6.03 & 0.1044 & 0.9427 & -0.0008 & 0.8279 & 470 \\
\hline$a_{p h}(670)$ & 0.2552 & -5.27 & -0.0814 & 0.9534 & -0.1496 & 0.8881 & 470 \\
\hline$a_{p h}(683)$ & 0.2802 & -4.25 & -0.0704 & 0.9354 & -0.1728 & 0.8747 & 470 \\
\hline Average & 0.2507 & 2.994 & 0.0314 & 0.9918 & 0.0114 & 0.8648 & 470 \\
\hline \multicolumn{8}{|c|}{ Carder In situ Data Set } \\
\hline$a_{p h}(412)$ & 0.1904 & 5.14 & 0.0718 & 0.8123 & -0.2039 & 0.8481 & 477 \\
\hline$a_{p h}(443)$ & 0.1847 & 5.01 & 0.0677 & 0.8008 & -0.2148 & 0.8443 & 477 \\
\hline$a_{p h}(490)$ & 0.1919 & 4.66 & 0.072 & 0.7977 & -0.2551 & 0.8453 & 477 \\
\hline$a_{p h}(510)$ & 0.216 & 5.05 & 0.0889 & 0.8081 & -0.266 & 0.8491 & 477 \\
\hline$a_{p h}(555)$ & 0.2912 & 5.61 & 0.1237 & 0.7847 & -0.3779 & 0.8196 & 477 \\
\hline$a_{p h}(675)$ & 0.2461 & -2.21 & -0.0466 & 0.8834 & -0.2866 & 0.8291 & 477 \\
\hline Average & 0.22 & 3.877 & 0.0629 & 0.8145 & 0.2674 & 0.8393 & 477 \\
\hline \multicolumn{8}{|c|}{ NOMAD SeaWiFS Satellite-Matchups Data Set } \\
\hline$a_{p h}(412)$ & 0.2135 & 6.24 & 0.0912 & 0.7702 & -0.2657 & 0.7952 & 102 \\
\hline$a_{p h}(443)$ & 0.2029 & 4.91 & 0.0694 & 0.74 & -0.3165 & 0.7993 & 102 \\
\hline$a_{p h}(490)$ & 0.2174 & 5.15 & 0.0829 & 0.7403 & -0.3566 & 0.7855 & 102 \\
\hline$a_{p h}(510)$ & 0.2416 & 5.38 & 0.0987 & 0.7497 & -0.3847 & 0.7979 & 102 \\
\hline$a_{p h}(530)$ & 0.2894 & 6.91 & 0.1422 & 0.7468 & -0.4149 & 0.7948 & 102 \\
\hline$a_{p h}(555)$ & 0.3462 & 8.29 & 0.1902 & 0.7188 & -0.5084 & 0.7745 & 102 \\
\hline$a_{p h}(670)$ & 0.2932 & 1.09 & 0.0231 & 0.7175 & -0.5832 & 0.7848 & 102 \\
\hline$a_{p h}(683)$ & 0.3304 & 2.17 & 0.0493 & 0.69 & -0.6697 & 0.7748 & 102 \\
\hline Average & 0.2668 & 5.018 & 0.0934 & 0.7342 & -0.4375 & 0.7884 & 102 \\
\hline
\end{tabular}


the wavelengths from $412 \mathrm{~nm}-683 \mathrm{~nm}$, producing low statistical errors (RMSE 0.2038 - 0. 3038 with an average of 0.2507 , MRE- $5.270 \%-8.06 \%$ with an average of $\sim 3.0 \%$, slope $0.935-1.048, \mathrm{R}^{2} 0.8279-0.888$, intercept values-0.172 - 0.13 ). These results confirm that the $a_{p h}(\lambda)$ predicted by the model at all these wavelengths matched closely with their corresponding in-situ $a_{p h}(\lambda)$ values very well, although slightly deviating from linearity at the higher end which may be due to problems with the in-situ data sampling techniques.

\subsubsection{Comparison with Carder In-Situ Data Set}

The in-situ $a_{p h}(\lambda)$ made by Carder and his colleagues in a wide range of coastal and oceanic waters were used to assess the performance of the new model. Figure 5 compares the model estimates of $a_{p h}(\lambda)$ with the in-situ measurements of $a_{p h}(\lambda)$. The statistical results are summarized in Table 2 for all the selected wavelengths from 412 to $683 \mathrm{~nm}$. Note that the model $a_{p h}(\lambda)$ values show very good agreement with in-situ $a_{p h}(\lambda)$ coefficient values at 412, 443, 490, 555, and $670 \mathrm{~nm}$, with low statisticcal errors (RMSE $0.184-0.291$ with an average of 0.22 , MRE-2.21\% - 5.14\% with an average of $\sim 3.87 \%$, slope $0.784-0.883, \mathrm{R}^{2} 0.819-0.849$, intercept values -0.203 -0.377). Compared with the previous validation, the RMSE is low, but other statistics become slightly worse.
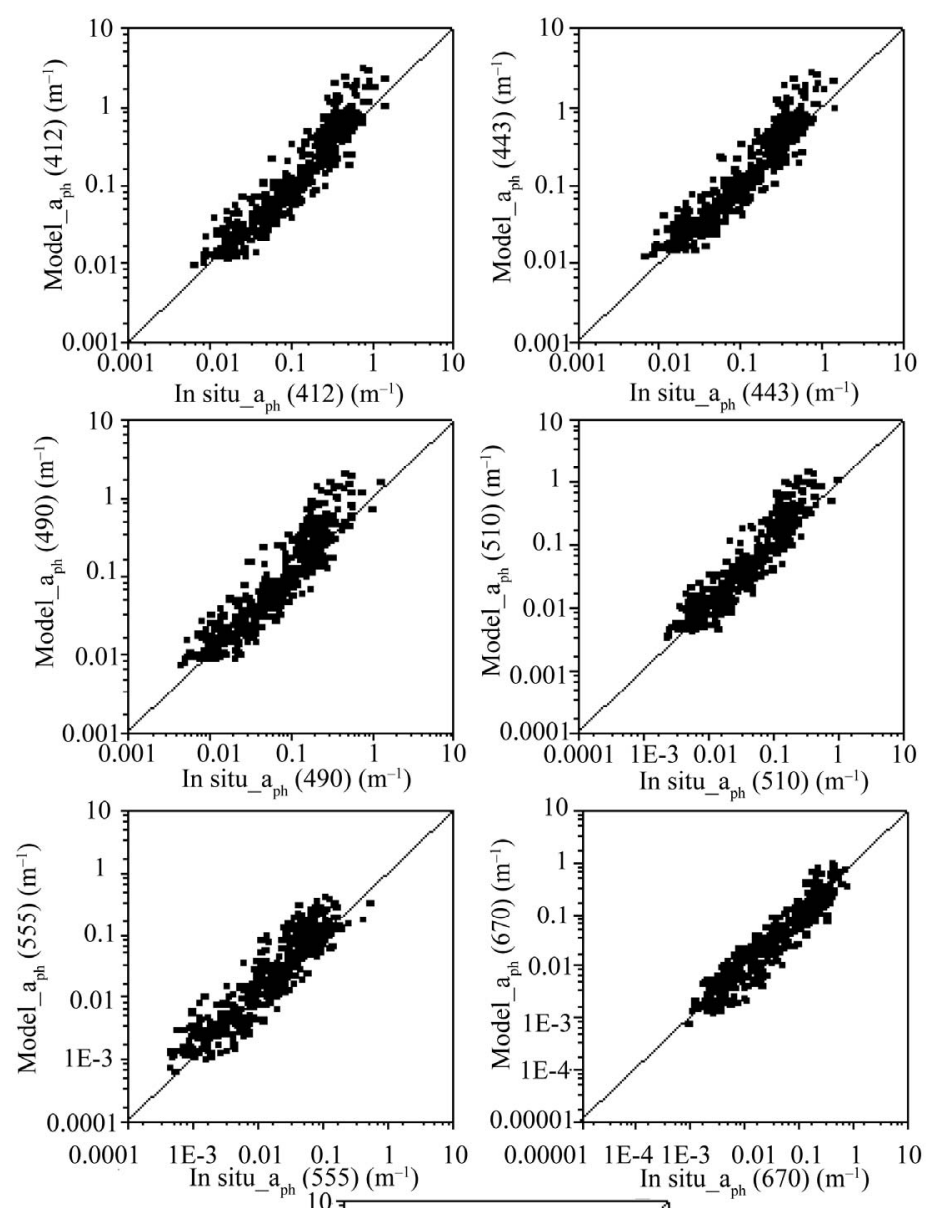

Figure 4. Comparison of modelled $a_{p h}(\lambda)$ with in-situ data taken from the NOMAD-2 database at wavelengths from 412 to 683 $(\mathrm{N}=\mathbf{4 7 0})$. 
However, the scatters of data are closely aligned with the 1:1 line indicating the validity of the model.

\subsubsection{Comparison with SeaWiFS Satellite Data Set}

A validation of the model was also performed by comparing satellite (SeaWiFS) estimates of $a_{p h}(\lambda)$ with concurrent in-situ $a_{p h}(\lambda)$ measurements. Figure 6 shows the scatter plots of the predicted $a_{p h}(\lambda)$ values versus the in-situ values. Table 2 presents the statistical analysis results at the wavelengths from 412 to $683 \mathrm{~nm}$. When applied to the SeaWiFS match-up remote sensing reflectance, it can be seen that the $a_{p h}(\lambda)$ values from the model closely agree with the in-situ data, without much scatters above or below the 1:1 line. The good agreement between these data sets can also be observed in Table 2 (RMSE 0.202 - 0. 34 with an average of 0.26, MRE $1.09 \%-8.29 \%$ with an average of $\sim 5.01 \%$ ), slope 0.69 $0.77, \mathrm{R}^{2} 0.774-0.797$, and intercept values -0.66 -0.26). Although these errors are slightly higher than those observed with the previous data sets, the model still produced the observed $a_{p h}(\lambda)$ values and resulted in low statistical errors. These results clearly indicate that the new model has the potential to retrieve accurately the $a_{p h}(\lambda)$ values in both clear and turbid coastal waters, and would be useful for applications with remote sensing data in these waters.

\subsubsection{Error Plots}

Figure 7 provides greater clarity in the variations of MRE between the derived and in-situ values of $a_{p h}(\lambda)$ at $412 \mathrm{~nm}-683 \mathrm{~nm}$. Though the MRE values for the new model are notably small at all wavelengths for the three independent data sets, it shows a significant variability across these wavelengths. For the NOMAD-2 data set, the MRE value is high at $412 \mathrm{~nm}(\sim 8.06 \%)$, and gradually decreases towards the longer wavelengths. By contrast, for the Carder and SeaWiFS match-up data sets, the MRE values are low in the blue wavelengths, increasing at the green wavelengths and sharply decreasing towards the longer wavelengths. However, these values are still in
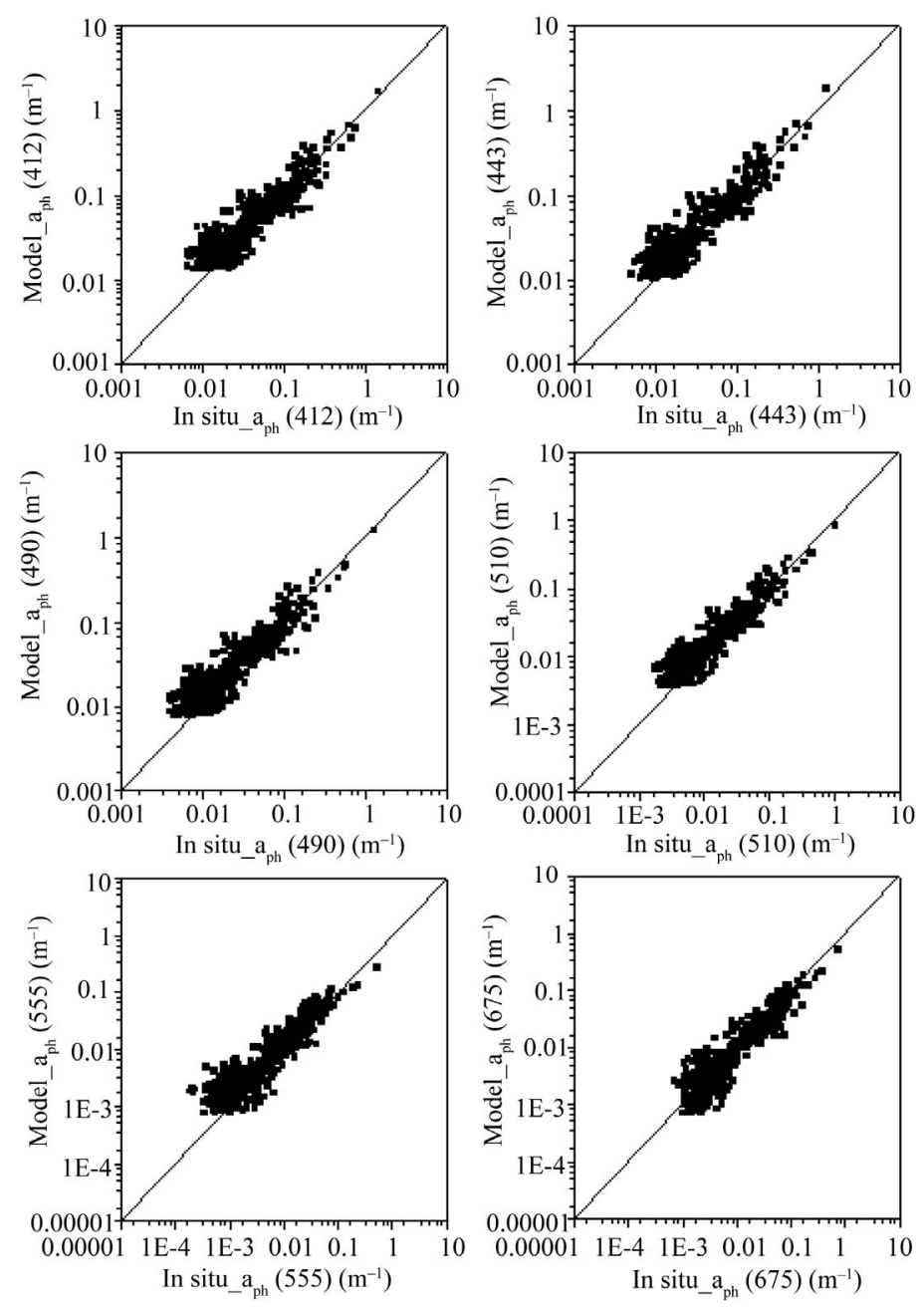

Figure 5. Comparison of modelled $a_{p h}(\lambda)$ with in-situ data taken from the Carder database at wavelengths from 412 to 675 (N = 477). 

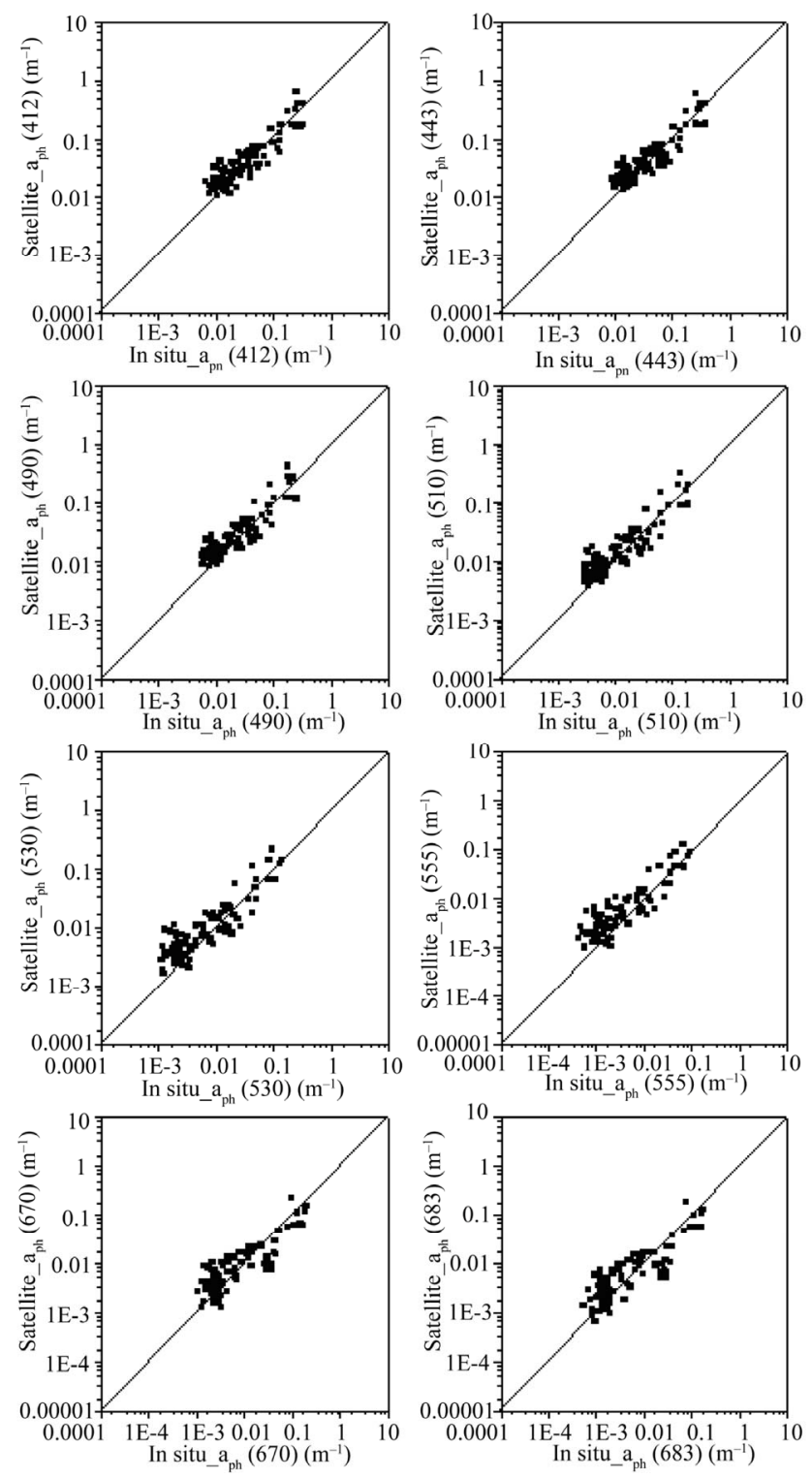

Figure 6. Comparisons of the modelled $a_{p h}(\lambda)$ with those from the in-situ dataset (NOMAD SeaWiFS match-ups dataset) at the wavelengths from 412 to $683 \mathrm{~nm}(\mathrm{~N}=102)$.

the acceptable range as far as the $a_{p h}(\lambda)$ modeling is concerned, because the current models produce very high errors in moderately turbid to highly turbid coastal waters [28].

\subsection{Application to Satellite Ocean Colour Data}

To further assess the efficiency of the new $a_{p h}$ model, the MODIS-Aqua Level 1A ( 1 km/pixel at nadir) imagery acquired over bloomed waters of the Arabian Sea on 18 February 2010, was processed using a regional Complex water Atmospheric correction Algorithm Scheme (CAAS) [27] to avoid known issues with the SeaDAS atmospheric correction algorithm in these waters. Subsequently, the proposed model was applied to the atmospherically corrected imagery to envisage the phytoplankton absorption coefficients at 443 and $670 \mathrm{~nm}$. Figure 8(a) and Figure 8(b) show the regional distribution patterns of $a_{p h}$ (443) and $a_{p h}(670)$ in the Arabian Sea. As expected, the distribution patterns illustrate the influence of coastal waters on the phytoplankton absorption coefficients across the entire Arabian Sea during 18 Feb. 2010. Figure 8(c) presents an example of $a_{p h}$ spectra from this new model using the same MODIS-Aqua data, which typically have two peaks (same as the measured $a_{p h}$ spectra) around 443 and $670 \mathrm{~nm}$. There is relatively lower absorption between 550 and $650 \mathrm{~nm}$. These peaks and troughs are essentially due to the presence of Chl pigment. The width of the peaks around 443 and $670 \mathrm{~nm}$ varies from sample to sample, due to the change in accessory pigments present and 

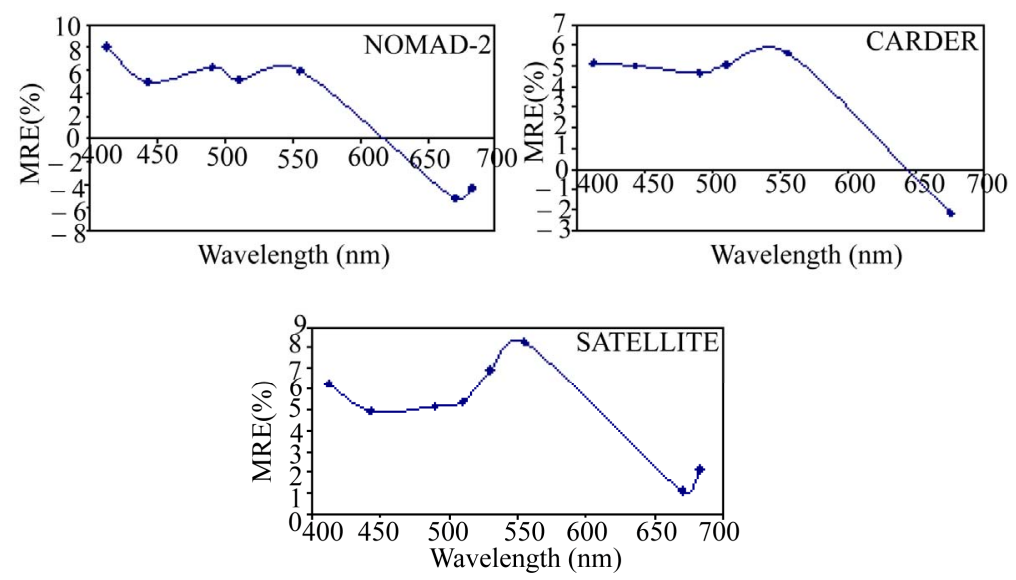

Figure 7. MRE between the derived and the in-situ values of coefficients of absorption by phytoplankton $a_{p h}(\lambda)$ for the new model.

the "package effect" [29-33]. These results indicate that the spectral variations of the phytoplankton absorption are reasonably good, both in terms of the spectral shape and magnitude in the visible wavelengths domain.

This satellite imagery was selected as a good example to address the atmospheric correction related issues. Figure 9(a) displays a typical distribution of sun glint measured at $551 \mathrm{~nm}$ and confirms that the glint contaminated portion of the image extends across the bloomed region in the central Arabian Sea. It is apparent that the density of mineral aerosol (desert) dust is not uniform, and it is very strong in the vicinity of desert coasts and across the Arabian Sea. The corresponding true colour composite (Band 253) for this area which was atmospherically corrected by the CAAS algorithm removes all these effects (Figure 9(b)). One of the typical problems with the SeaDAS atmospheric correction algorithm is that it produces negative water-leaving radiance $\left(L_{w}\right)$ values in optically complex waters (containing plumes and blooms). This problem is clearly seen in Figure 9(c), where the SeaDAS algorithm often rendered negative $L_{w}$ in the blue, or created a cloud or a complete atmospheric correction failure because of the elevated NIR radiances. Most of the surface algal blooms present always non-zero values at the NIR bands and near-zero values (sometime negatives) at the short-wavelengths bands (e.g. $412 \mathrm{~nm}$ ). It is clear that the spectral curvatures between 488 and $551 \mathrm{~nm}$ are retained in the SeaDAS $L_{w}$ during the low bloom condition. However, the curvatures are not present in the $L_{w}$ spectra (i.e. large distortions in $L_{w}$ structures with high negative values across the wavebands) during the high bloom (surface) condition. The dramatic anomalous negative $L_{w}$ values could be attributed to the black-pixel assumption or inadequacy of the NIR correction scheme with the SeaDAS algorithm [27]. By contrast, the CAAS-derived $L_{w}$ are more realistic depicting the different stages of algal blooms, with the presence of a red edge in the NIR which is indicative of the dense mats of floating phytoplankton similar to land vegetation.

\subsection{Implications for the Optical Remote Sensing}

Changes in the concentration and composition of the water constituents, due to biological, chemical or physical processes, affect light penetration in the water and the spectral signature of light that leaves the water surface. In open ocean waters (Case-1 type), which are usually deep and free of terrestrial influence, variations in optical properties are linked to phytoplankton and their by-products. These are major constituents affecting changes in the spectral signature of water-leaving radiance. In Case 2 waters, which include most coastal regions, the concentrations of the optically significant constituents can vary independently of each other. Interpreting optical remote sensing signals from such waters is particularly challenging $[34,35]$, as it can be seen with the standard algorithms frequently producing erroneous results. The problem is amplified by the fact that the atmospheric correction algorithms used for marine remote sensing assume zero reflectance in the near infra-red, which is not valid for turbid waters. However, the knowledge and understanding of phytoplankton absorption coefficients are limited by the present algorithms, although these data have significant effects on global bio-product in the ocean and to the carbon cycle. Therefore, obtaining the spectral absorption coefficients $a_{p h}(\lambda)$ of phytoplankton on a regional and global scale is important for studies on the ocean's role in the global biological production, carbon cycle and climate change [36]. In order to use ocean-colour measurements to derive information on the concentration and composition of optically active substances in the water, it is necessary to develop bio-optical algorithms that relate the water-leaving radiance to the optical properties of the substances present in the water. The determination of bio-geo-physical parameters, such as chlo- 

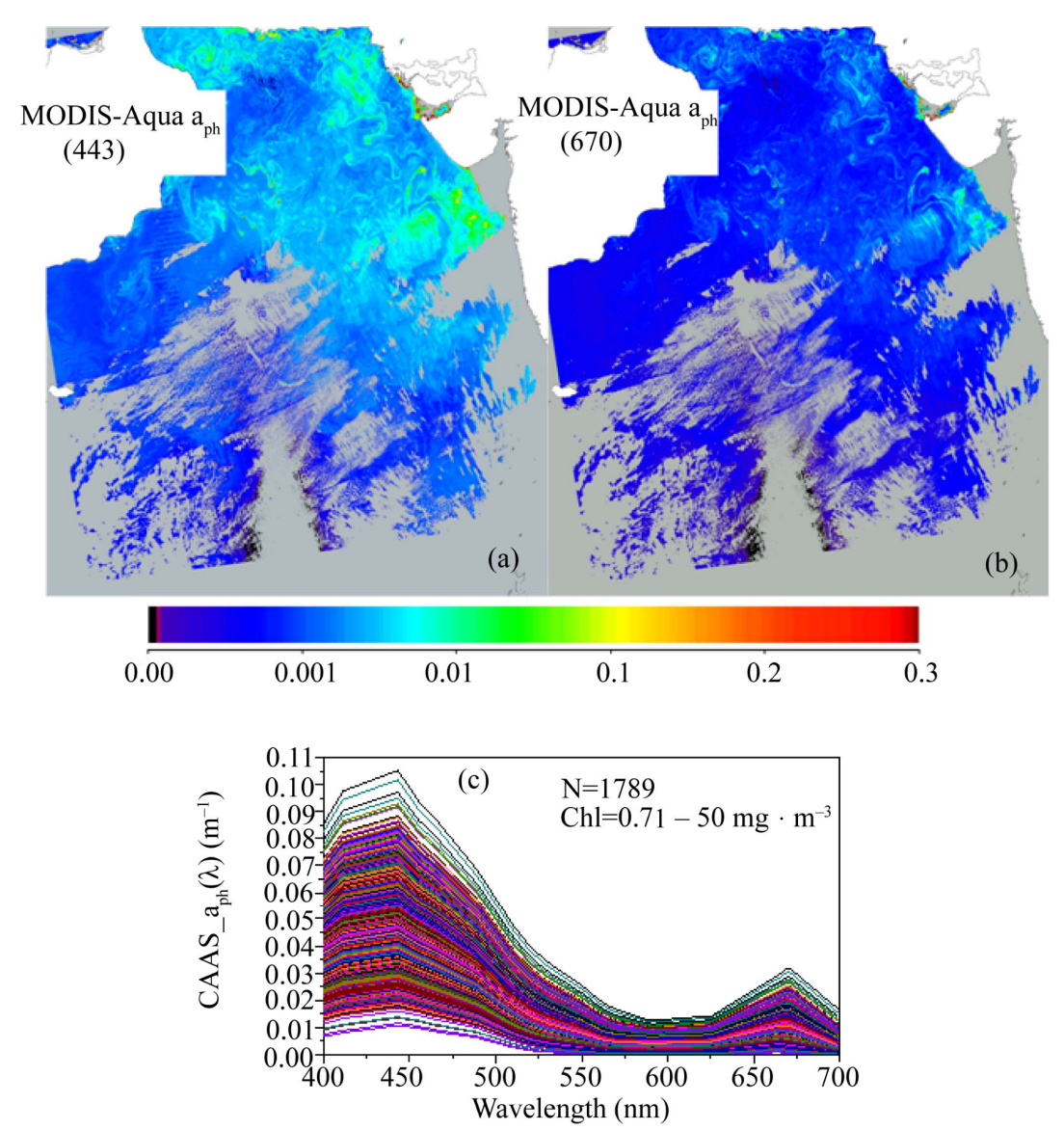

Figure 8. (a,b) MODIS/AQUA data for $18^{\text {th }}$ February 2010 over Arabian Sea, showing the model implementation for the fields of $a_{p h}(443)$ and $a_{p h}(670)$, (c) $a_{p h}$ spectra obtained using the CAAS estimated reflectance values.

rophyll concentration, based on water-leaving radiances, is relatively less complex for Case 1 waters where the spectral signature of the emerging light is mostly affected by phytoplankton and their by-products. The situation is very different in Case 2 coastal and estuarine waters that are characterized by higher optical and biological complexity, since other substances such as detritus, mineral particles, dissolved organic and inorganic material, also affect the light signal measured by the satellite sensor. The new $a_{p h}(\lambda)$ model when applied with the CAAS algorithm particularly provides more reliable $a_{p h}$ products for coastal and estuarine waters.

\section{Discussion}

Though a wide variety of models-with varying degrees of complexity ranging from empirical to complex semi -analytical approaches-for determination of the $a_{p h}(\lambda)$ coefficients were developed in the past, no models have the potential to provide reliable $a_{p h}(\lambda)$ products in coastal waters. Thus, accurate estimation of $a_{p h}(\lambda)$ in these waters is still a daunting challenge. Hoge et al. [37,38] found that $a_{p h}(\lambda)$ products at the wavelengths of 490,510 and $555 \mathrm{~nm}$ are often estimated with large errors, when derived from a linear matrix inversion model. In another study, $a_{p h}(675)$ was obtained by an inversion model using the spectral remote sensing reflectance ratio between 412:443 and 443:551, which assumed the values of several algebraic constraints [30]. $a_{p h}(675)$ values were determined by fitting a hyperbolic tangent function to $a_{p h}(675)$ and defaulted to an empirical band ratio algorithm when solution was not reached. Many other reflectance-based models (inversion models) are also available in the literature such as QAA, LM, and GSM [19]. However, these models are applicable only in clear oceanic waters, and provide no $a_{p h}$ data at the longer wavelengths (in the red domain). This could be because of the fact that the total absorption coefficient is generally dominated by pure seawater in oceanic waters, except for eutrophic waters when $a_{p h}(\lambda)$ makes significant contributions to the total absorption coefficients $(a(\lambda))$. Other limitations are that the derivation of $a_{p h}$ at some specific wavelengths using one set of equations and at other wavelengths using different equations. After a thorough investigation and comparison of our results with those from the other models (not shown for brevity since it is already discussed in Shanmugam et al. [28], it was found 

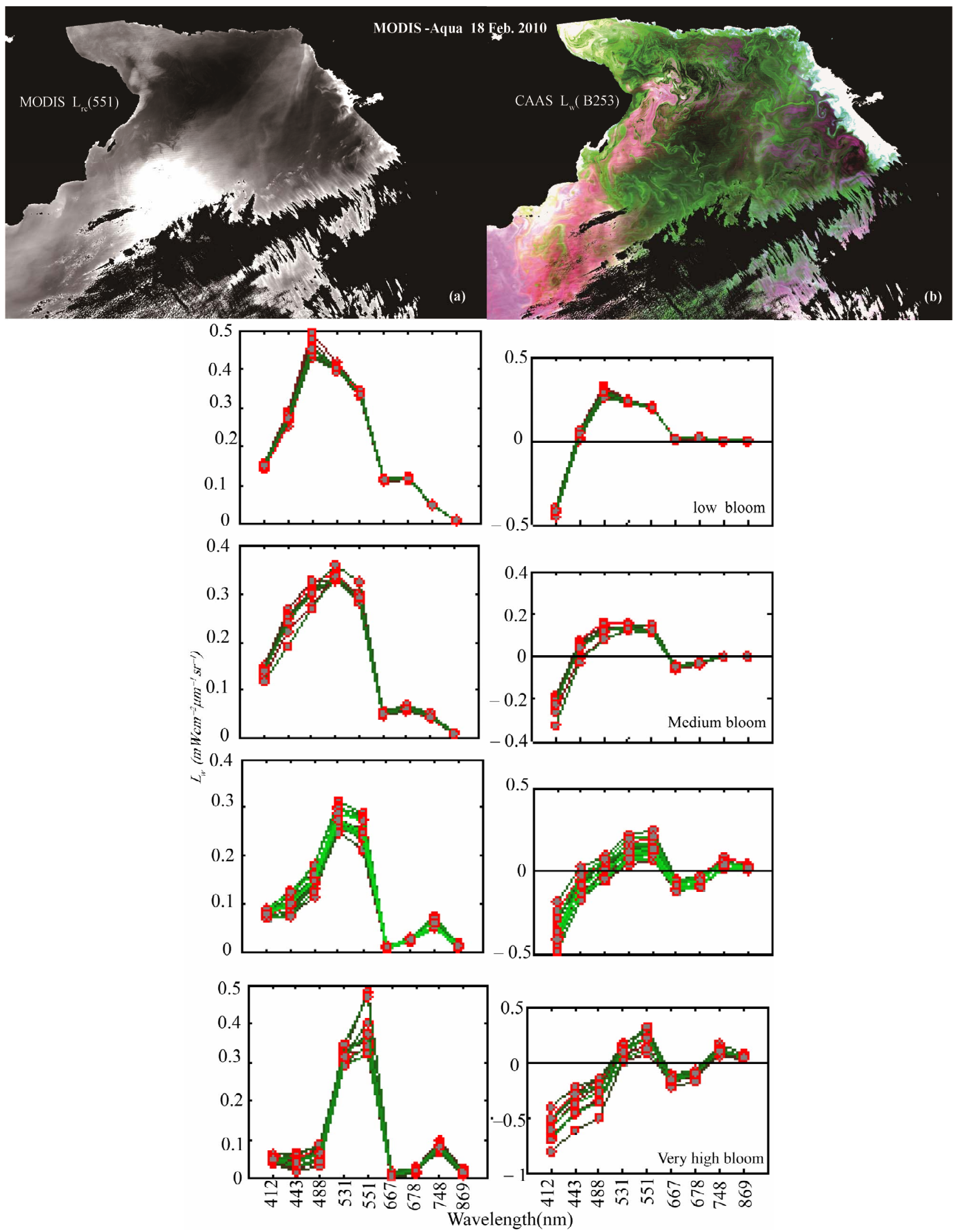

Figure 9. MODIS/AQUA data for $18^{\text {th }}$ February 2010 over Arabian Sea, showing the spectral variation of radiance retrieved from CAAS and SeaDAS in case of Low bloom, Medium bloom, High bloom, and Very high bloom waters. 
that the new model is inherently more flexible for determination of $a_{p h}$ coefficients at any wavelengths in the visible domain.

\section{Conclusion}

The new model has significant advantages over other models, since it relies on the $R_{r s}(670) / R_{r s}(490)$ ratio which is not significantly influenced by materials other than phytoplankton. Validation of the model with independent in-situ data sets gave encouraging results. The model-predicted $a_{p h}(\lambda)$ values were found to be in good agreement with in-situ data from coastal/oceanic waters. The model wavelengths of the SeaWiFS sensor (412 to $683 \mathrm{~nm}$ ). Though the errors were low (e.g., MRE 8\%), scatter plots showed slight differences between the model and in-situ $a_{p h}(\lambda)$ values. The difference may arise due to several reasons; for instance, $R_{r \mathrm{~s}}(\lambda)$ measurements made with different instruments with different calibration and correction procedures as well as environmental conditions. It was demonstrated that the atmospheric correction of satellite ocean colour data could introduce very high errors in complex waters. However, such problems could be eliminated when the water-leaving radiance signals are estimated with the CAAS algorithm. Thus, the $a_{p h}(\lambda)$ model may be applied along with the CAAS algorithm, in order to retrieve more reliable $a_{p h}(\lambda)$ values in optically complex waters. A MODIS-Aqua example showed striking features of the distribution pattern of phytoplankton absorption coefficients in bloomed waters in the Arabian Sea. In conclusion, this is the first study to estimate $a_{p h}(\lambda)$ values at all the visible wavelengths. Thus, it provides new opportunities for improving the phytoplankton inversion modelling based on the coefficients as given in Table 1. Our future effort will include additional validation and tests based on more in-situ and satellite data, and refining the model coefficients in order to provide more accurate phytoplankton absorption coefficients in complex waters.

\section{Acknowledgements}

This work was supported by INCOIS under the grant (OEC/1011/102/INCO/PSHA) of the SATCORE program. The authors would like to thank the NASA Ocean Biology Processing Group for making available the global, high quality bio-optical (NOMAD) data set and the LAC MODIS-Aqua to this study. The authors would like to thank J. P. Cannizzaro and C. Hu for providing the bio-optical datasets of Prof. K. L. Carder.

\section{REFERENCES}

[1] A. Morel and L. Prieur, "Analysis of Variations in Ocean
Colour," Limnology and Oceanography, Vol. 22, No. 4, 1977, pp. 709-722. doi:10.4319/10.1977.22.4.0709

[2] A. Morel and S. Maritorena, "Bio-Optical Properties of Oceanic Waters: A Reappraisal," Journal of Geophysical research, Vol. 106, No. C4, 2001, pp. 7163-7180. doi:10.1029/2000JC000319

[3] H. R. Gordon, O. B. Brown, R. H. Evans, J. W. Brown, R. C. Smith, K. S. Baker and D. K. Clark, "A Semi-Analytic Model of Ocean Colour," Journal of Geophysical Research, Vol. 9, No. D9, 1988, pp. 10909-10924. doi:10.1029/JD093iD09p10909

[4] A. Morel, "Optical Modeling of the Upper Ocean in Relation to Its Biogenous Matter Content (Case I Waters)," Journal of Geophysical Research, Vol. 93, No. C9, 1988, pp. 10749-10768. doi:10.1029/JC093iC09p10749

[5] T. Platt and S. Sathyendranath, "Oceanic Primary Production: Estimation by Remote Sensing at Local and Regional Scales," Science, Vol. 241, No. 4873, 1988, pp. 1613-1620. doi:10.1126/science.241.4873.1613

[6] H. M. Sosik and B. G. Mitchell, "Light Absorption by Phytoplankton, Photosynthetic Pigments and Detritus in the California Current System," Deep Sea-Research, Vol. 42, No. 10, 1995, pp. 1717-1748. doi:10.1016/0967-0637(95)00081-G

[7] E. H. S. Van Duin, G. Blom, F. J. Los, R. Maffione, R. Zimmerman, C. F. Cerco, D. Mark, E. P. H. Best, Van Duin, et al., "Modeling Underwater Light Climate in Relation to Sedimentation, Resuspension, Water Quality and Autotrophic Growth," Hydrobiologia, Vol. 444, No. 1-3, 2001, pp. 25-42. doi:10.1023/A:1017512614680

[8] A. Morel, B. Gentili, M. Chami and J. Ras, "Bio-Optical Properties of High Chlorophyll Case 1 Waters, and of Yellow-Substance-Dominated Case 2 Waters," Deep-Sea Research Part I, Vol. 53, No. 9, 2006, pp. 1439-1559. doi:10.1016/j.dsr.2006.07.007

[9] N. Hoepffner and S. Sathyendranath, "Determination of the Major Groups of Phytoplankton Pigments from the Absorption Spectra of Total Particulate Matter," Journal of Geophysical Research, Vol. 98, No. C12, 1993, pp. 22789-22804. doi:10.1029/93JC01273

[10] A. Ciotti, M. R. Lewis and J. J. Cullen, "Assessment of the Relationship between Dominant Cell Size in Natural Phytoplakton Communities and the Spectral Shape of the Absorption Coefficient," Limnology and Oceanography, Vol. 47, No. 2, 2002, pp. 404-417. doi:10.4319/10.2002.47.2.0404

[11] J. R. Moisan, T. A. H. Moisan and M. A. Linkswiler, “An Inverse Modeling Approach to Estimating Phytoplankton Pigment Concentrations from Phytoplankton Absorption Spectra," Journal of Geophysical Research, Vol. 116, No. C09018, 2011.

[12] L. Prieur and S. Sathyendranath, "An Optical Classification of Coastal and Oceanic Waters Based on the Specific Spectral Absorption Curves of Phytoplankton Pigments, Dissolved Organic Matter, and Other Particulate Materials," Limnology and Oceanography, Vol. 26, No. 4, 1981, pp. 671-689. doi:10.4319/1o.1981.26.4.0671

[13] E. Millan-Nunez, M. E. Sieracki, R. Millan-Nunez, J. R. 
Lara-Lara, G. Gaxiola-Castro and C. C. Trees, "Specific Absorption Coefficient and Phytoplankton Biomass in the Southern Region of the California Current," Deep Sea Research, Part II, Vol. 51, No. 6-9, 2004, pp. 817-826. doi:10.1016/i.dsr2.2004.05.023

[14] S. A. Garver and D. Siegel, "Inherent Optical Property Inversion of Ocean Colour Spectra and Its Biogeochemical Interpretation 1. Time Series from the Sargasso Sea," Journal of Geophysical Research, Vol. 102, No. C8, 1997, pp. 18607-18625. doi:10.1029/96JC03243

[15] S. Maritorena, D. A. Siegel and A. R. Peterson, "Optimization of a Semianalytical Ocean Colour Model for Global-Scale Applications," Applied Optics, Vol. 41, No. 15, 2002, pp. 2705-2714. doi:10.1364/AO.41.002705

[16] Z. P. Lee, K. L. Carder and R. Arnone, "Deriving Inherent Optical Roperties from Water Colour: A Multi-Band Quasi-Analytical Algorithm or Optically Deep Waters," Applied Optics, Vol. 41, No. 27, 2002, pp. 5755-5772. doi:10.1364/AO.41.005755

[17] P. Shanmugam, Y. H. Ahn, J. H. Ryu and B. Sundarabalan, "An Evaluation of Inversion Models for Retrieval of Inherent Optical Properties from Ocean Colour in Coastal and Open Sea Waters around Korea," Journal of Oceanography, Vol. 66, No. 6, 2010, pp. 815-830. doi:10.1007/s10872-010-0066-0

[18] T. J. Smyth, G. F. Moore, T. Hirata and J. Aiken, "Semianalytical Model for the Derivation of Ocean Colour Inherent Optical Properties: Description, Implementation, and Performance Assessment," Applied Optics, Vol. 45, No. 31, 2006, pp. 8116-8131. doi:10.1364/AO.45.008116

[19] E. Boss and C. Roesler, "Over Constrained Linear Matrix Inversion with Tatistical Selection," In: Z. Lee, Ed., Remote Sensing of Inherent Optical Properties: Fundamentals, Tests of Algorithms, and Applications, IOCCG, Dartmouth, NS, Canada, IOCCG Rep. 5, 2006.

[20] H. C. van de Hulst, "Light Scattering by Small Particles," Dover, Mineola, 1981, $470 \mathrm{p}$.

[21] R. W. Preisendorfer, "Application of Radiative Transfer theory to Light Measurements in the Sea," Union of Geodetic Geophysical Institute Monograph, Vol. 10, 1961, pp. 11-30.

[22] M. Pope and E. S. Fry, "Absorption Spectrum (380 - 700 $\mathrm{nm})$ of Pure Water. II. Integrating Cavity Measurements," Applied Optics, Vol. 36, No. 33, 1997, pp. 8710-8723. doi:10.1364/AO.36.008710

[23] R. C. Smith and K. S. Baker, "Optical Properties of the Clearest Natural Waters," Applied Optics, Vol. 20, No. 2, 1981, pp. 177-184. doi:10.1364/AO.20.000177

[24] A. Bricaud, A. Morel and L. Prieur, "A Absorption by Dissolved Organic Matter in the Sea (yellow substance) the UV and Visible Domains," Limnology and Oceanography, Vol. 26, No. 1, 1981, pp. 43-53. doi:10.4319/10.1981.26.1.0043

[25] A. Bricaud, M. Babin, A. Morel and H. Claustre, "Variability in the Chlorophyll-Specific Absorption Coefficients of Natural Phytoplankton: Analysis and Parameterization," Journal of Geophysical Research, Vol. 100, No. C7, 1995, pp. 13321-13332.

\section{doi:10.1029/95JC00463}

[26] A. Bricaud, A. Morel, M. Babin, K. Allali and H. Claustre, "Variations of Light Absorption by Suspended Particles with Chlorophyll a Concentration in Oceanic (Case 1) Waters: Analysis and Implications for BioOptical Models," Journal of Geophysical Research, Vol 103, No. C13, 1998, pp. 31033-31044. doi:10.1029/98JC02712

[27] P. Shanmugam, "CAAS: An Atmospheric Correction Algorithm for the Remote Sensing of Complex Waters," Annales Geophysicae, Vol. 30, No. 1, 2012, pp. 203-220. doi:10.5194/angeo-30-203-2012

[28] P. Shanmugam, Y. H. Ahn, J. H. Ryu and B. Sundarabalan, "An Evaluation of Inversion Models for Retrieval of Inherent Optical Properties from Ocean Colour in Coastal and Open Sea around Korea," Journal of Oceanography, Vol. 66, 2010, pp. 815-830. doi:10.1007/s10872-010-0066-0

[29] K. L. Carder, S. K. Hawes, K. A. Baker, R. C. Smith, R. G. Steward and B. G. Mitchell, "Reflectance Model for Quantifying Chlorophyll a in the Presence of Productivity Degradation Products," Journal of Geophysical Research , Vol. 96, No. C11, 1991, pp. 599-611. doi:10.1029/91JC02117

[30] K. L. Carder, F. R. Chen, Z. P. Lee, S. K. Hawes and D. Kamykowski, "Semianalytic Moderate-Resolution Imaging Spectrometer Algorithms for Chlorophyll-a and Absorption with Bio-Optical Domains Based on Nitrate Depletion Temperatures," Journal of Geophysical Research, Vol. 104, No. C3, 1999, pp. 5403-5421. doi:10.1029/1998JC900082

[31] C. S. Yentsch and D. A. Phinney, "Spectral Fluorescence: An Ataaxonomic Tool for Studying the Structure of Phytoplankton Populations," Journal of Plankton Research, Vol. 7, No. 5, 1985, pp. 617-632. doi:10.1093/plankt/7.5.617

[32] C. S. Yentsch and D. A. Phinney, "A Bridge between Ocean Optics and Microbial Ecology," Limnology and Oceanography, Vol. 34, No. 8, 1989, pp. 1694-1705. doi:10.4319/10.1989.34.8.1694

[33] J. E. O'Reilly, S. Moritorena, B. G. Mitchell, D. S. Seigel, K. L. Carder, S. A. Garver, et al., "Ocean Colour Chlorophyll Algorithms for SeaWiFS," Journal of Geophysical Research, Vol. 103, No. C11, 1998, pp. 937-953.

[34] R. Miller, C. Del-Castillo and B. McKee, "Remote Sensing of Coastal Aquatic Environments," Springer, Dordrecht, 2005, p. 347. doi:10.1007/978-1-4020-3100-7

[35] S. Sathyendranath, Ed., "Remote Sensing of Ocean Colour in Coastal, and Other Optically Complex Waters," Reports of the International Ocean-Colour Coordinating Group, IOCCG, Dartmouth, NS, Canada, Rep. 3, 2000, p. 140.

[36] M. Tzortziou, A. Subramaniam, J. R. Herman, C. L. Gallegos, P. J. Neale and H. L. W. Jr., "Remote Sensing Reflectance and Inherent Optical Properties in the Mid Chesapeake Bay," Estuarine, Coastal and Shelf Science, Vol. 72, No. 1-2, 2007, pp. 16-32. doi:10.1016/j.ecss.2006.09.018

[37] F. E Hoge and P. E. Lyon, "Satellite Retrieval of Inherent 
Optical Properties by Linear Matrix Inversion of Oceanic Radiance Models: An Analysis of Model and Radiance Measurements," Journal of Geophysical Research, Vol. 101, No. C7, 1996, pp. 16631-16648.

doi:10.1029/96JC01414
[38] F. E. Hoge and P. E. Lyon, "Spectral Parameters of Inherent Optical Property Models: Method for Satellite Retrieval by Matrix Inversion of an Oceanic Radiance Model," Applied Optics, Vol. 38, No. 9, 1999, pp. 1657-1662. doi:10.1364/AO.38.001657 